\title{
Changes in Typhoon Activities and Regional Precipitation Variability over the Korean Peninsula according to Different Phases of El Niño
}

\author{
Jong-Suk Kim, ${ }^{1,2}$ Sun-Kwon Yoon, ${ }^{3}$ Sang Myeong $O h^{3}$ and Young-Il Moon ${ }^{1,2}$ \\ ${ }^{1}$ Department of Civil Engineering, University of Seoul, Seoul 130-743, Republic of Korea \\ ${ }^{2}$ Urban Flood Research Institute, University of Seoul, Seoul 130-743, Republic of Korea \\ ${ }^{3}$ Climate Research Department, APEC Climate Center, Busan 612-020, Republic of Korea
}

Correspondence should be addressed to Young-Il Moon; ymoon@uos.ac.kr

Received 30 June 2014; Accepted 3 November 2014

Academic Editor: Francisco J. Tapiador

Copyright (C) 2015 Jong-Suk Kim et al. This is an open access article distributed under the Creative Commons Attribution License, which permits unrestricted use, distribution, and reproduction in any medium, provided the original work is properly cited.

\begin{abstract}
We analyzed typhoon activities such as tropical cyclone (TC) genesis position, movement routes and central pressure of typhoons, and changes in local patterns of rainfall stemming from TCs passing through the Korean domain. The results showed a remarkable difference in changes in typhoons that affect the Korean Peninsula (KP) during cold tongue (CT) and warm pool (WP) El Niño years. In particular, TCs that move through the ocean off Korea and the Kuroshio during WP El Niño years are relatively stronger than TCs formed during CT El Niño years. Furthermore, analysis of large-scale atmosphere-ocean dynamics showed better conditions for TC development and strengthening during WP El Niño years. TC-induced summer rainfall over major Korean river basins decreased from normal years during CT El Niño years $(-3.94 \%)$ and increased over normal years during WP El Niño years $(+33.92 \%)$. The results of this diagnostic study rely on short-term observations and relatively little data, but they suggest that CT/WP El Niño cycles influence TC activities and rainfall across the KP. The findings are important for reducing TC damage and ensuring a proper response to climate change in coupled human-environmental systems.
\end{abstract}

\section{Introduction}

Tropical cyclones (TCs) in the western North Pacific (WNP) are hydrometeorological features that control East Asian summer precipitation patterns [1-5]. WNP TCs have affected the Korean Peninsula (KP) directly and indirectly, causing 530 deaths and approximately 1.1 trillion won in property damage from 1990 to 2011 [6]. Research into climate change based on the latest high-resolution dynamic models is projecting the probability of a gradual increase in the frequency and intensity of tropical cyclones in the WNP during the 21st century [7-9]. Accordingly, interest in TCs is increasing, and the identification of change in the local characteristics of rainfall related to TCs is becoming the most important factor in terms of the efficient management of disaster and water resources [10-12].

Sea surface temperatures (SSTs) are a key control on the occurrence and intensity of TCs. Recent higher than usual SSTs in the tropical Pacific Ocean off Peru and west of Ecuador have led to a change in cycle, intensity, and genesis of El Niño that is unlike the traditional cold tongue (CT) El Niño [13-16]. The new type of El Niño, known as warm pool (WP) El Niño, is associated with Central Pacific sea surface temperatures that are abnormally high in comparison to the western and eastern regions of the Pacific sea. The explicit cause of WP El Niño occurrence has yet to be determined [1719], though the influence of El Niño on WNP TCs has been extensively investigated [2, 20-25]. Relatively little research has been conducted to quantify the impacts of CT/WP El Niño on Korea-affected TC activities or regional variability in TC-induced precipitation over the Korean peninsula. Yoon et al. [26] have explored the effect of WP/CT Niño events on seasonal precipitation and runoff in the Han River basin, Korea. They found that water resources during the spring and summer in the Han River basin are very sensitive to WP El Niño events, but not as sensitive to CT El Niño events. 


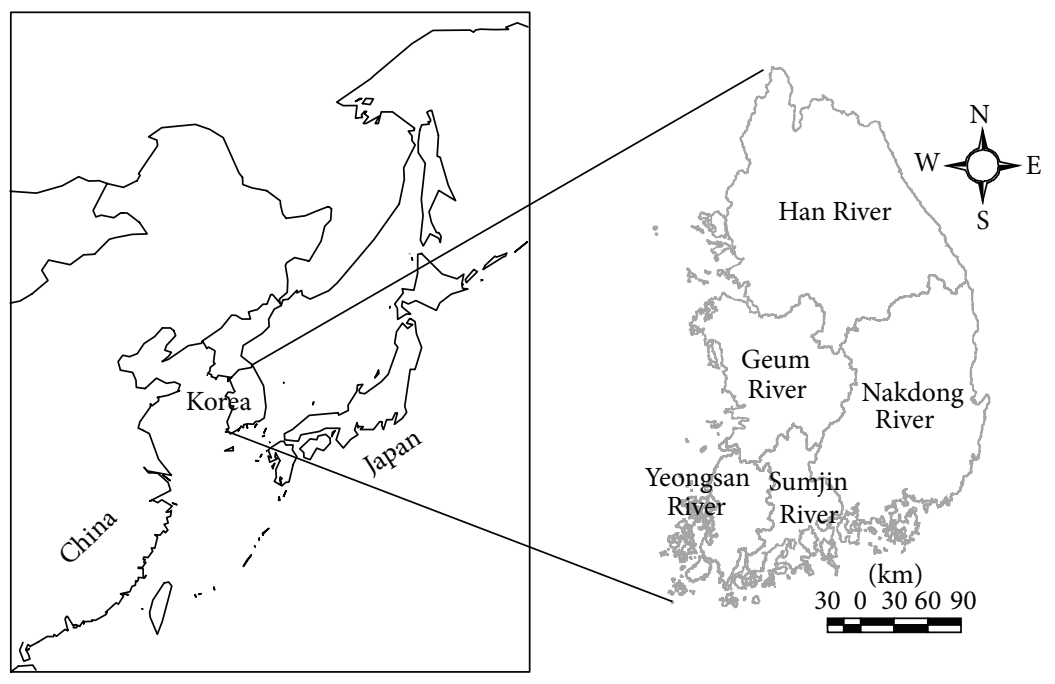

(a) Five major river basins in Korea

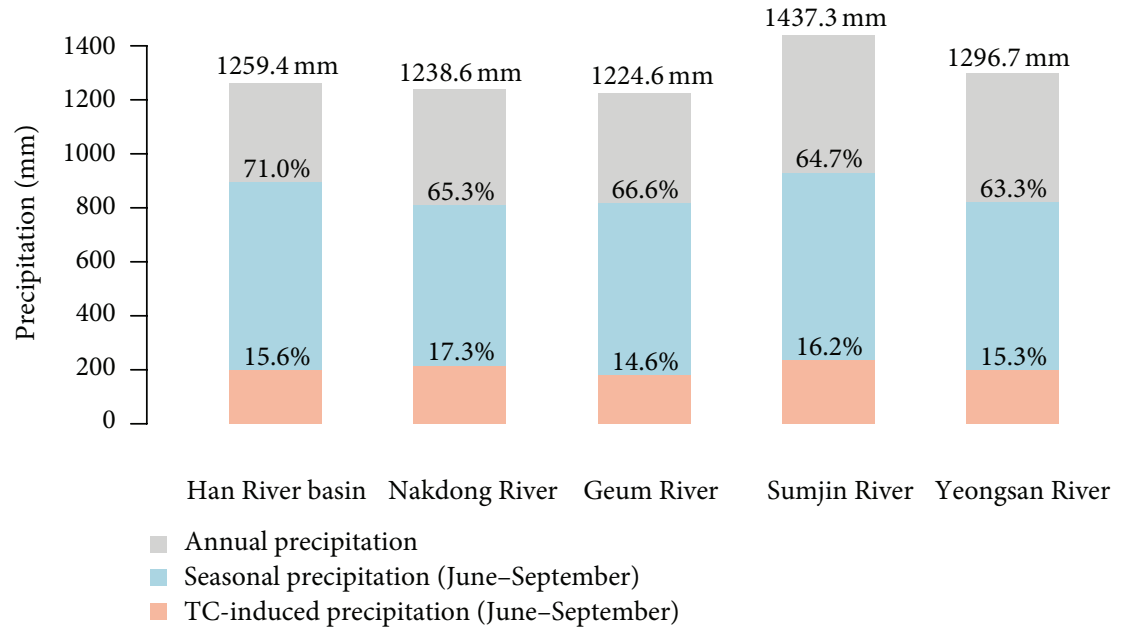

(b) Distribution of seasonal precipitation

FIGURE 1: Distribution of seasonal precipitation (June-September) in Korea during the 1966-2007 periods. (a) Five major river basins in Korea. (b) Distribution of seasonal precipitation. The annual long-term average precipitation was noted with the number for each histogram. The fraction of seasonal precipitation and TC-induced precipitation is expressed in percentage.

Extreme rainfall, caused by an episodic event such as a typhoon, has a great effect on the structure and maintenance of river ecosystem equilibrium. Therefore, it is necessary to examine these events more closely [27-29]. In addition, despite increasing frequency and intensity of TCs in the WNP region, quantitative research into changes of local characteristics in KP has thus far been unsatisfactory. This study aims to examine changes in the local characteristics caused by the effects of TC activity on the KP, according to El Niño type, offer basic information for preparing flood control and disaster prevention solutions for mid- to longterm water resource forecast and management, and provide realistic solutions for prevention of casualties by conducting an analysis of summer typhoons and extreme rainfall.

\section{Materials and Methods}

2.1. Study Area. Figure 1 is a map of the KP showing the location of the study area as well as the classification of five major river basins in Korea. It also shows the contribution of summer and typhoon related rainfall to average annual rainfall for each river basin form 1966 to 2007. The Han River basin is composed of 29 subbasins, and $51.3 \%$ of the total population of South Korea resides in this basin area. The basin area totals $38,421.8 \mathrm{~km}^{2}$, and the average annual rainfall is $1259.4 \mathrm{~mm}$. Of the average annual rainfall, $71.0 \%$ occurs in the summer, and rainfall from typhoons in this period accounts for $15.6 \%$ of the average annual rainfall. The Nakdong River basin is composed of 33 subbasins, with 


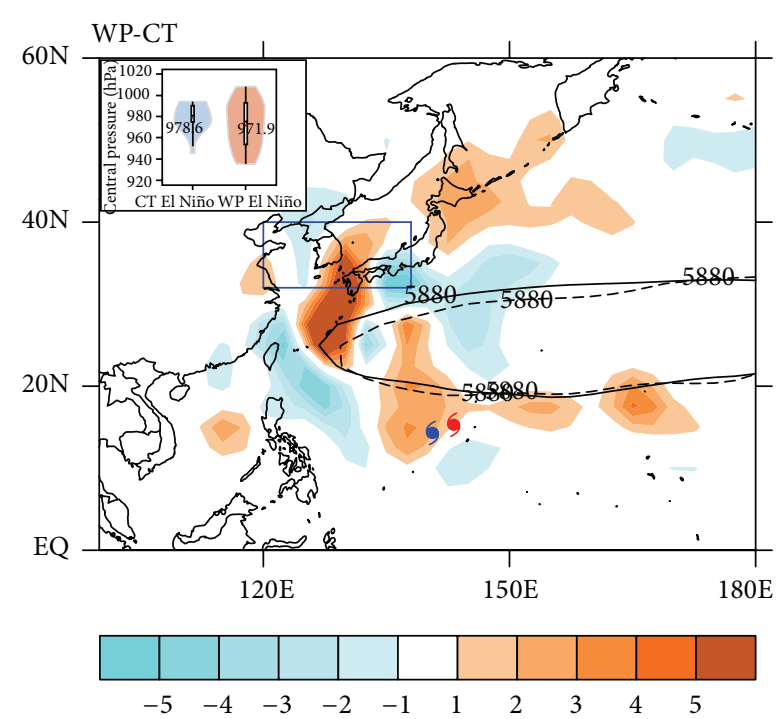

FIGURE 2: Composite differences of tropical cyclones (TCs) passed through the Korean domain (shown in a solid blue line) during CT and WP El Niño years. The solid (dashed) line indicates the seasonal mean (June-September) of the WNP subtropical high (5880 gpm) during the WP (CT) El Niño years. Mean TC genesis positions were shown by typhoon symbols in blue (red) during the CT El Niño years (WP El Niño years). Inset: empirical probability distribution for central pressure ( $\mathrm{hPa}$ ) of TCs. Violin plots (box plot-density trace synergism) were applied for central pressure $(\mathrm{hPa})$ of TCs affecting the Korean Peninsula during CT/WP El Niño years. Numbers inside the inset represent the average value of central pressure of TCs for each case.

an area of $31,712.0 \mathrm{~km}^{2}$ and an average annual rainfall of $1238.6 \mathrm{~mm}$. Typhoon rainfall contribution is highest in this basin, with $17.3 \%$ of the average annual rainfall occurring intensively between June and September. The Geum River basin, located in the mid-western region, records $1244.6 \mathrm{~mm}$ of average annual rainfall and has the smallest portion of rainfall from typhoons ( $14.6 \%$ of average annual rainfall). It is composed of a total of 21 subbasins (with a total basin area of $\left.17,357 \mathrm{~km}^{2}\right)$. The Sumjin River basin $\left(8,299.1 \mathrm{~km}^{2}\right)$ and the Yeongsan River basin $\left(7,598.7 \mathrm{~km}^{2}\right)$, located in the southern region, have the highest occurrences of average annual rainfall among the five major river basins. In particular, typhoon rainfall in the Sumjin River basin accounts for $16.2 \%$ of the average annual rainfall $(1437.3 \mathrm{~mm})$; thus, this area is classified as the region that is most affected by typhoons.

According to statistical data from 1971 to 2011 (WAMIS, [30]), more than $2 / 3$ of the entire flood damage (2.52 trillion won) in South Korea occurred in the Han River basin (35.0\%) and the Nakdong River basin (32.3\%). These areas were followed by the Geum River basin (15.6\%), the Sumjin River basin (9.1\%), and the Yeongsan River basin (8.0\%). In particular, damage from typhoons such as Rusa (2002) and Maemi (2003) was reported to have been extensive. Therefore, this study analyzes changes in the occurrence and intensity of typhoons, focusing on typhoons affecting the KP in the context of changes in the surface temperature of tropical seas (CT/WP El Niño), which may have the greatest effect on typhoon activity. Furthermore, the study provides basic data for the implementation of a predictive disaster-prevention system in preparation for typhoons through an analysis of the characteristics of changes in rainfall from typhoons according to region, aimed at the five major river basins in Korea.

2.2. Data and Methods. This study used data on rainfall in mid-size watersheds of the Korean Peninsula and SSTs, as well as data on typhoons generated in the WNP. First, data on average basin rainfall, calculated by the Thiessen polygon method, were obtained from the Korea Water Management Information System (WAMIS, [30]) for the 42-year period from 1966 to 2007. Second, observation data form the Climate Prediction Center (CPC) of the National Oceanic and Atmospheric Administration (NOAA, [31]) were used as Niño3 and Niño4 indices. These data are updated every month and can be downloaded from the CPC website (http://www.cpc.ncep.noaa.gov/data/indices/). SST data with grid size of latitude $1^{\circ}$ and longitude $1^{\circ}$ were obtained from the Met Office Hadley Centre $[32,33]$. For data on the TC track generated in the WNP, this study used the observation data (1966-2007) of the Korean Typhoon Research Center (TRC) and the Japan Meteorological Agency (JMA, [34]).

Ren and Jin [35] separated CT El Niño and WP El Niño from other types of El Niño events using observation data of Niño3 and Niño4, as is shown in the following:

$$
\begin{aligned}
& N_{\mathrm{CT}}=N_{3}-\alpha N_{4}, \\
& N_{\mathrm{WP}}=N_{4}-\alpha N_{3}, \\
& \alpha= \begin{cases}\frac{2}{5}, & N_{3} N_{4}>0, \\
0, & \text { otherwise }\end{cases}
\end{aligned}
$$

where $N_{3}$ and $N_{4}$ are the mean indexes of Niño3 and Niño4. $N_{\text {CT }}$ and $N_{\text {WP }}$ indicate CT El Niño and WP El Niño indexes, respectively. The symbol $\alpha$ is used as the correction factor for separating different El Niños. This study adopted the standard classification of CT El Niño and WP El Niño based on monthly Niño3 and Niño4 anomalies suggested by Ren and Jin [35]. We selected five strong CT El Niños (1972/1973, $1982 / 1983,1986 / 1987,1991 / 1992,1997 / 1998)$ and five strong WP El Niños (1968/1969, 1990/1991, 1994/1995, 2002/2003, $2004 / 2005)$ to clarify the changes in characteristics of summer rainfall generation by typhoons and different types of El Niño over the Korean Peninsula.

This study employed an exploratory analysis technique in order to classify seasonal rainfall by episodic TCs affecting $\mathrm{KP}[3,10]$; the technique considers rainfall on the basin, outflow response, and residence time of typhoons that pass the KP influence domain $\left(120^{\circ}-138^{\circ} \mathrm{E}, 32^{\circ}-40^{\circ} \mathrm{N}\right)$. In addition, composite analysis (CA) was mainly used in this study. To complement the relatively small number of events, we applied Student's $t$-test and the bootstrap random resampling method for 42 years (1966-2007) with observation data and verified statistical significance of regional rainfall characteristics of typhoons affecting KP according to CT/WP El Niño patterns. 


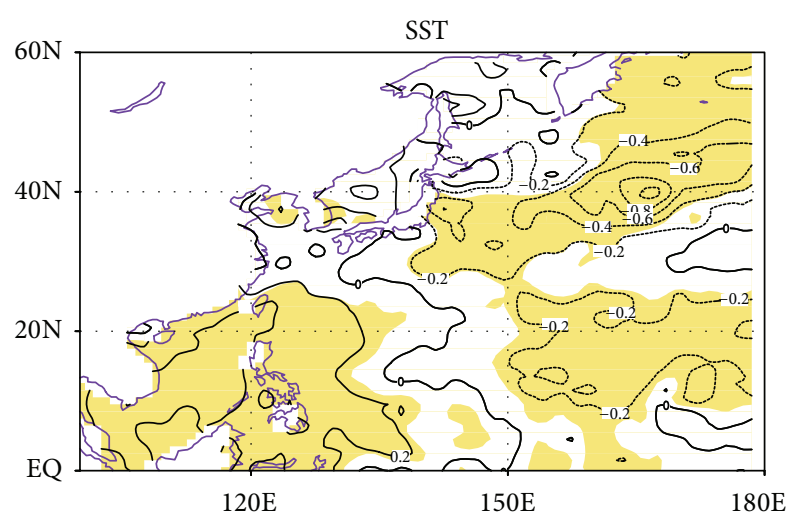

(a) CT years

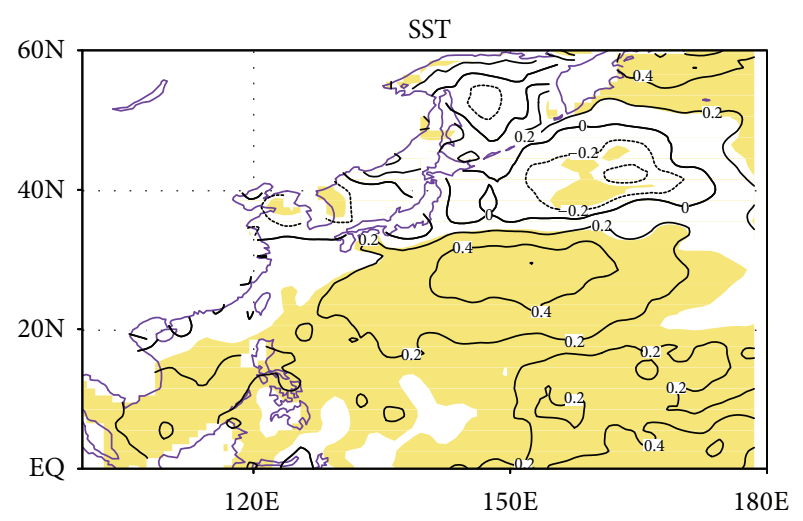

(b) WP years

FIGURE 3: SST-composed anomalies obtained from Hadley SST in (a) CT years and (b) WP years. Shading indicates values over 90\% confidence based on Student's $t$-test.

\section{Analysis and Results}

3.1. Changes in Typhoon Activities and Large-Scale Atmospheric Environments. Figure 2 illustrates the genesis point of a typhoon and its movement route in accordance with CT/WP El Niño for the period 1966-2007. An analysis of influential WNP typhoons that have passed over the KP domain $\left(120^{\circ}-138^{\circ} \mathrm{E}, 32^{\circ}-40^{\circ} \mathrm{N}\right)$ during CT El Niño years found that the average genesis points of TCs $\left(14.3^{\circ} \mathrm{N}, 140.6^{\circ} \mathrm{E}\right)$ of 208 typhoons is located south of the average genesis point of TCs $\left(15.8^{\circ} \mathrm{N}, 140.7^{\circ} \mathrm{E}\right)$. During WP El Niño years, average TC genesis location occurs southeast $\left(14.3^{\circ} \mathrm{N}, 143.2^{\circ} \mathrm{E}\right)$ of the total average. The movement route of typhoons frequently appeared to be widely spread and in an irregular zigzag pattern during CT El Niño years. During WP El Niño years, relatively powerful typhoons tended to move along the seas around the KP and along the Kuroshio. As shown in Figure 2 (inset), in the years of the CT El Niño, the peak of the probability density function is high and the variation is not very large (average: $978.6 \mathrm{hPa}$, coefficient of variation $(\mathrm{CV})$ : 0.013 ); thus, the intensity of a typhoon was found to be similar to that which occurs in long-term normal years. In the years of the WP El Niño, the peak of the probability density function is low and the central pressure variation of TCs was relatively large (average: $971.9 \mathrm{hPa}, \mathrm{CV}: 0.023$ ), but a little negatively skewed. As a result, it was determined that powerful TCs occurred frequently in the years of the WP El Niño.

We investigated variation in large-scale atmospheric environmental parameters in order to explain differences in typhoon activity between the two different El Niño patterns. Figure 3 shows SST anomalies (SSTA) for CT and WP years over the WNP. SSTs affect changes in the occurrence and intensity of KP TCs. During CT El Niño years (Figure 3(a)), variability of SSTs in the Philippines and in some regions of the southeast China Sea is higher in comparison to normal years. During WP El Niño years (Figure 3(b)), SSTAs are comparatively high across the WNP, except for an extended area incorporating the eastern Kuroshio off Japan and the coastal seas off the KP. These higher SSTAs should provide favorable conditions for TC development as latent heat generation might reinforce or maintain the intensity of TCs that migrate northward towards the KP after forming at low latitudes [36].

Figure 4 shows the vertical wind shear (VWS) anomalies during two CT/WP El Niño periods. VWS is associated with the occurrence of TCs in the main development region of the WNP and changes in the intensity of TCs that go north towards the middle latitudes. In particular, the VWS between latitudes $20^{\circ} \mathrm{N}$ and $35^{\circ} \mathrm{N}$ has been known to alter the intensity of TCs landing on the KP [37]. As shown in Figure 4(a), during the CT El Niño period, negative VWS anomalies appear to be narrow around latitude $20^{\circ}$, whereas a positive anomaly appears over latitude $25^{\circ}$. Meanwhile, during the WP El Niño period, negative VWS anomalies form a wider area from latitudes $20^{\circ} \mathrm{N}$ to $35^{\circ} \mathrm{N}$. We assume that this negative VWS zone can maintain or reinforce the intensity of TCs that go north towards the KP (Figure 4(b)). The results of the analysis above indicate that WP El Niño years provide better atmospheric environmental conditions for the development of KP-affected TCs compared to CT El Niño years.

3.2. Changes in Typhoon Precipitation over Korea. Data for two different CT/WP El Niño years allowed for a characteristic analysis of TC related rainfall over the five major South Korean river basins. Figure 5 shows the subbasin scale variability of Korean summer rainfall (June-September) caused by TCs during CT El Niño and WP El Niño years. During CT El Niño years (Case 1), the TC rainfall on the KP was $-3.94 \%$ lower than long-term norm (Han River: $-0.56 \%$, Nakdong River: 1.09\%, Geum River: -13.26\%, Sumjin River: 5.34\%, Yeongsan River: $-30.69 \%)$. Typhoon rainfall was decreased (increased) in the basins of the Han River (Nakdong River). The basins of the Yeongsan River, with a coefficient of variation (CV) of 0.49 , and the Sumjin River (CV: 0.47) showed the largest changes of the typhoon rainfall (Figure 5(a)). In WP El Niño years (Case 2), the anomaly of typhoon rainfall was substantially increased to $33.92 \%$ over the KP region (Han River: 36.22\%, Nakdong River: 32.25\%, Geum River: 35.01\%, 


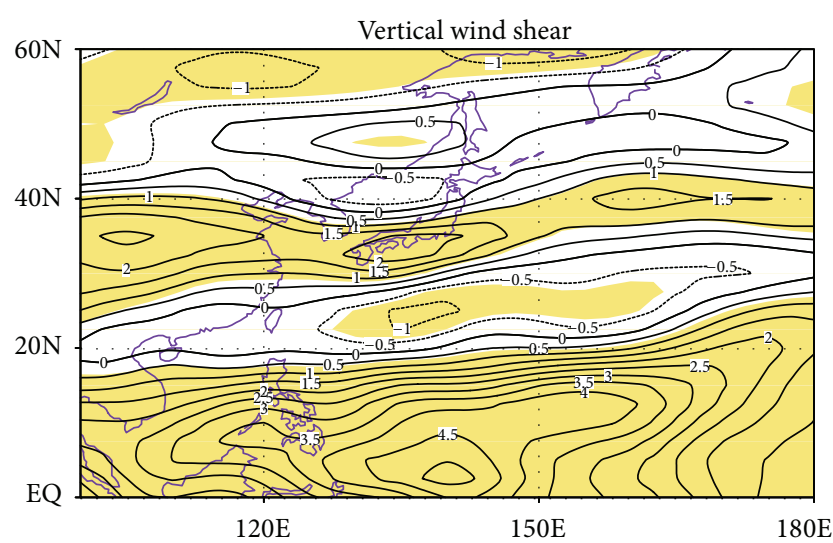

(a) CT years

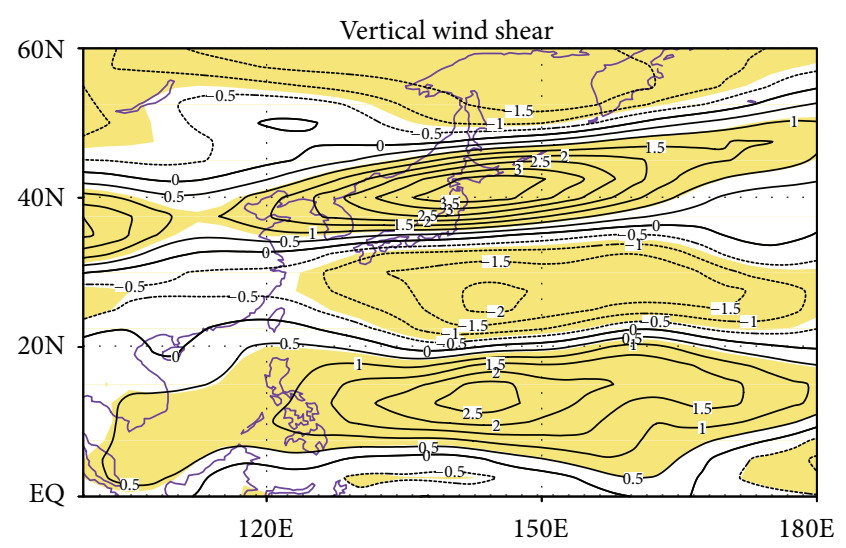

(b) WP years

FIGURE 4: Vertical wind shear anomalies obtained from NCEP-NCAR reanalysis in (a) CT years and (b) WP years. Shading indicates values over $90 \%$ confidence based on Student's $t$-test.

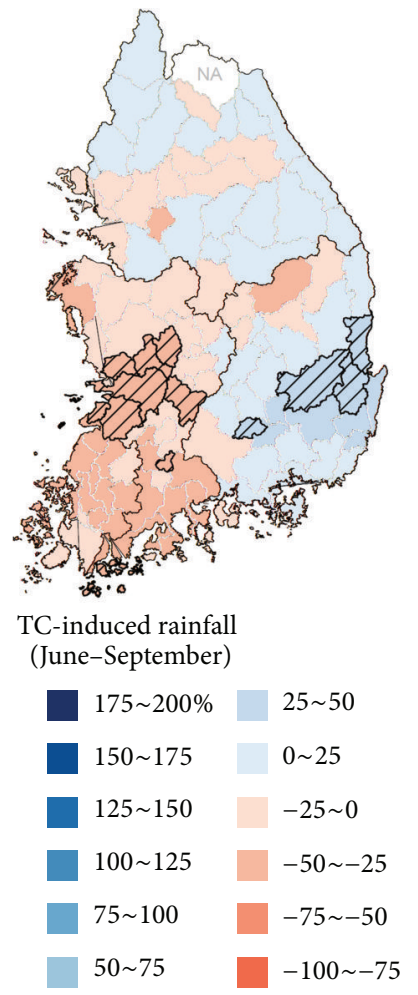

(a) Case 1 (CT El Nino)

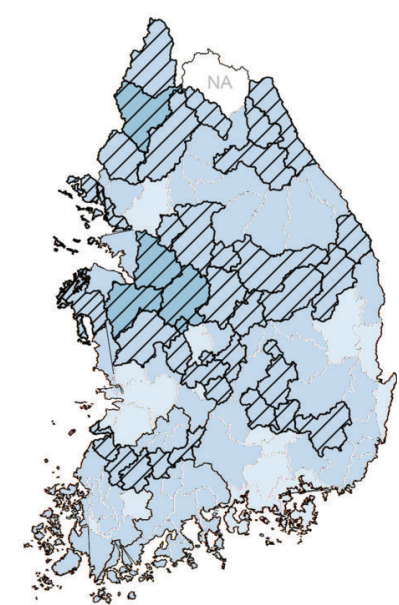

TC-induced rainfall (June-September)

$\begin{array}{ll}175 \sim 200 \% & 25 \sim 50 \\ 150 \sim 175 & 0 \sim 25 \\ 125 \sim 150 & -25 \sim 0 \\ 100 \sim 125 & -50 \sim-25 \\ 75 \sim 100 & -75 \sim-50 \\ 50 \sim 75 & -100 \sim-75\end{array}$

(b) Case 2 (WP El Nino)

FIGURE 5: Composite anomalies of TC-induced rainfall during CT/WP El Niño years. The hatched polygons indicate statistically significant changes in TC rainfall based on the $10 \%$ significance level. NA indicates data are not available.

Sumjin River: 28.85\%, Yeongsan River: 32.26\%). Of the basins of the five major rivers, $41.78 \%$ (39 out of 112 basins) revealed statistically significant increasing patterns all over the KP. The $\mathrm{CV}$ range of $0.23-0.38$ is lower than those in CT El Niño years (Figure 5(b)).

Figure 6 shows that heavy rain day ( $\geq 50 \mathrm{~mm} /$ day) most frequently occurred during typhoons in CT/WP El Niño years. It also shows a similar pattern to Figure 5 for changes in TC-induced summer rainfall in the KP region. During CT El Niño years (Case 1), the frequency of heavy rain days in the southwestern area tends to be decreased, but is increased near the Han and Nakdong river basins (Figure 6(a)). During WP El Niño years (Case 2), the frequency of heavy rain days from typhoons over all areas, excluding some parts, was 


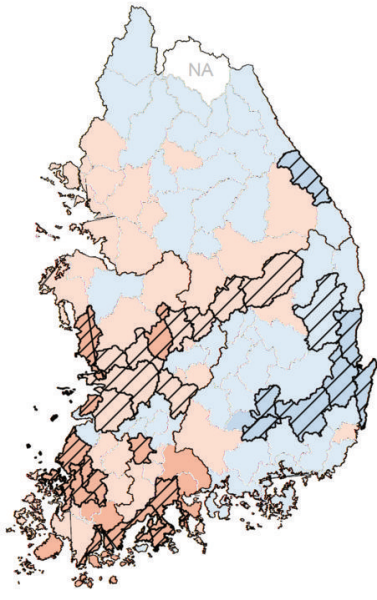

Number of days $(>50 \mathrm{~mm} /$ day $)$

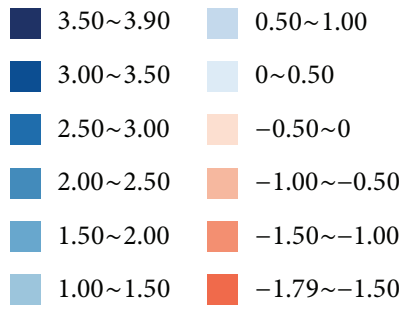

(a) Case 1 (CT El Nino)

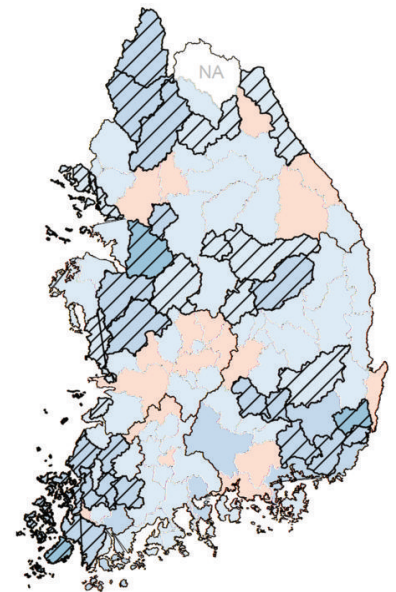

Number of days $(>50 \mathrm{~mm} /$ day $)$

\begin{tabular}{|l|l}
\hline $3.50 \sim 3.90$ & $0.50 \sim 1.00$ \\
$3.00 \sim 3.50$ & $0 \sim 0.50$ \\
\hline $2.50 \sim 3.00$ & $-0.50 \sim 0$ \\
\hline $2.00 \sim 2.50$ & $-1.00 \sim-0.50$ \\
$1.50 \sim 2.00$ & $-1.50 \sim-1.00$ \\
$1.00 \sim 1.50$ & $-1.79 \sim-1.50$
\end{tabular}

(b) Case 2 (WP El Nino)

FIGURE 6: Composite anomalies of TC-related heavy rain days ( $\geq 50 \mathrm{~mm} /$ day) during CT/WP El Niño years. The hatched polygons indicate statistically significant changes in TC-induced rainy days based on the $10 \%$ significance level. NA indicates data are not available.

relatively high. In $30.60 \%$ of subbasins (32 out of 112 ), the increasing pattern was analyzed to be statistically significant (Figure 6(b)).

\section{Summary and Conclusions}

This study focused on the behavior of CT/WP El Niño associated typhoons that affect the KP. We analyzed typhoon activity, related rainfall, and the frequency of heavy rainy days in summer over the five major river basins in Korea. The summary of the main results is as follows.

(1) Analysis of KP associated typhoon activity and occurrence from 1966 to 2007 indicates that in comparison to the total average typhoon genesis location, average CT El Niño typhoon genesis is situated to the south $\left(14.3^{\circ} \mathrm{N}, 140.6^{\circ} \mathrm{E}\right)$ and average WP El Niño typhoon genesis is situated to the southeast $\left(14.3^{\circ} \mathrm{N}, 143.2^{\circ} \mathrm{E}\right)$. The movement routes of typhoons during the CT El Niño years are relatively wide, with irregular zigzag patterns. During WP El Niño years, the relatively stronger typhoons tend to move throughout the ocean off Korea and the Kuroshio.

(2) Analysis of the large-scale environmental conditions associated with CT/WP El Niño revealed that the atmosphere-ocean environment during WP El Niño years offers better conditions for typhoon development than in CT El Niño years. In particular, comparison of the SSTs (a direct heat source for typhoons) with the atmosphere environment showed a remarkable difference. Marine conditions in the northwest Pacific give continuous latent heat to typhoons coming into the KP domain, helping typhoons to sustain strength created in low latitudes and developed while moving into the midlatitude of Korea. VWS near the latitude $25^{\circ} \mathrm{N}$ during WP El Niño years provides favorable conditions to develop and strengthen typhoons coming up to Korea. Vertical velocity and divergence in the midlatitudes contribute to the ability of typhoons to maintain strength as they approach Korea. Overall, the large-scale environment during WP El Niño years offers better conditions for the development and strengthening of typhoons than during CT El Niño years.

(3) The TC-induced summer rainfall in the five major river basins in Korea decreased by $-3.94 \%$ from norms (1966-2007) during CT El Niño years and increased $33.92 \%$ during WP El Niño years. TCinduced rainfall during CT El Niño years decreased in the southwestern area, including the Geum River basin, and increased in the basins of the Han River and the Nakdong River. On the contrary, TC-induced rainfall during WP El Niño years increased over 
the entire KP region. This change is similar to the frequency of heavy rain days $(\geq 50 \mathrm{~mm} /$ day) stemming from typhoons.

Presently, the National Typhoon Center (NTC, http:// typ.kma.go.kr/) independently monitors typhoons occurring in the basins of the Korean Peninsula, from their development to dissipation, for the sake of forecasts. In addition, the National Emergency Management Agency (NEMA, http://eng.nema.go.kr/) investigates damages to lives and properties caused by typhoons. In fact, research to anticipate the track and strength of typhoons in the Atlantic region is being actively conducted by many scientists. However, less research is available in the Northwest Pacific.

The findings of this study rely on short-term observations and limited data; however, they suggest that CT/WP El Nino affects the activity and rainfall intensity of typhoons influencing the Korean Peninsula. Follow-up research to examine the evolving patterns of surface sea temperature (SST) and the tracks and strengths of typhoons according to largescale atmospheric circulations can contribute to typhoon forecasting. This study shows the spatial characteristics of typhoon-induced rainfall in Korea. This information can be applied to model and forecast flooding, which in turn can be used for adaptation activities at the basin scale.

\section{Conflict of Interests}

The authors declare that there is no conflict of interests regarding the publication of this paper.

\section{Acknowledgment}

This research was supported by a Grant (no. 13AWMPB066744-01) from Advanced Water Management Research Program (AWMP) funded by the Ministry of Land, Infrastructure and Transport of the Korean government.

\section{References}

[1] K. S. Choi, C. C. Wu, and E. J. Cha, "Change of tropical cyclone activity by pacific-Japan teleconnection pattern in the Western North Pacific," Journal of Geophysical Research, vol. 115, no. D19, Article ID D19114, 2010.

[2] K.-S. Choi and I.-J. Moon, "Influence of the Western Pacific teleconnection pattern on Western North Pacific tropical cyclone activity," Dynamics of Atmospheres and Oceans, vol. 57, pp. 1-16, 2012.

[3] J.-S. Kim, R. C.-Y. Li, and W. Zhou, "Effects of the Pacific-Japan teleconnection pattern on tropical cyclone activity and extreme precipitation events over the Korean peninsula," Journal of Geophysical Research, vol. 117, no. D18, 2012.

[4] J. Y. Tu, C. Chou, P. Huang, and R. Huang, "An abrupt increase of intense typhoons over the western North Pacific in early summer," Environmental Research Letters, vol. 6, no. 3, Article ID 034013, 2011.

[5] H. Weng, K. Ashok, S. K. Behera, S. A. Rao, and T. Yamagata, "Impacts of recent El Niño Modoki on dry/wet conditions in the Pacific rim during boreal summer," Climate Dynamics, vol. 29, no. 2, pp. 113-129, 2007.
[6] NDIC (National Disaster Information Center), http://www .safekorea.go.kr/.

[7] K. Emanuel, "Environmental factors affecting tropical cyclone power dissipation," Journal of Climate, vol. 20, no. 22, pp. 54975509, 2007.

[8] K. Manuel, R. Sundararajan, and J. Williams, "Hurricanes and global warming: results from downscaling IPCC AR4 simulations," Bulletin of the American Meteorological Society, vol. 89, no. 3, pp. 347-367, 2008.

[9] T. R. Knutson, J. L. McBride, J. Chan et al., "Tropical cyclones and climate change," Nature Geoscience, vol. 3, no. 3, pp. 157-163, 2010.

[10] J. S. Kim and S. Jain, "Precipitation trends over the Korean peninsula: typhoon-induced changes and a typology for characterizing climate-related risk," Environmental Research Letters, vol. 6, no. 3, Article ID 034033, 2011.

[11] J.-S. Kim, W. Zhou, X. Wang, and S. Jain, "El Niño Modoki and the summer precipitation variability over South Korea: a diagnostic study," Journal of the Meteorological Society of Japan, vol. 90, no. 5, pp. 673-684, 2012.

[12] J.-S. Kim, S. Jain, and S.-K. Yoon, "Warm season streamflow variability in the Korean Han River Basin: Links with atmospheric teleconnections," International Journal of Climatology, vol. 32, no. 4, pp. 635-640, 2012.

[13] K. Ashok, S. K. Behera, S. A. Rao, H. Weng, and T. Yamagata, "El Niño Modoki and its possible teleconnection," Journal of Geophysical Research C: Oceans, vol. 112, no. 11, Article ID C11007, 2007.

[14] H.-Y. Kao and J.-Y. Yu, "Contrasting Eastern-Pacific and Central-Pacific types of ENSO," Journal of Climate, vol. 22, no. 3, pp. 615-632, 2009.

[15] P. K. Pradhan, B. Preethi, K. Ashok, R. Krishnan, and A. K. Sahai, "Modoki, Indian Ocean Dipole, and western North Pacific typhoons: possible implications for extreme events," Journal of Geophysical Research D: Atmospheres, vol. 116, no. 18, Article ID D18108, 2011.

[16] S.-W. Yeh, J.-S. Kug, B. Dewitte, M.-H. Kwon, B. P. Kirtman, and F.-F. Jin, "El Niño in a changing climate," Nature, vol. 461, pp. 511-514, 2009.

[17] C. H. Ho, J. J. Baik, J. H. Kim, D. Y. Gong, and C. H. Sui, "Interdecadal changes in summertime typhoon tracks," Journal of Climate, vol. 17, no. 9, pp. 1767-1776, 2009.

[18] A. V. Newman, G. Hayes, Y. Wei, and J. Convers, “The 25 October 2010 Mentawai tsunami earthquake, from real-time discriminants, finite-fault rupture, and tsunami excitation," Geophysical Research Letters, vol. 38, no. 5, Article ID L05302, 2011.

[19] C.-Y. Son, J.-S. Kim, Y.-I. Moon, and J.-H. Lee, "Characteristics of tropical cyclone-induced precipitation over the Korean River basins according to three evolution patterns of the CentralPacific El Niño," Stochastic Environmental Research and Risk Assessment, vol. 28, no. 5, pp. 1147-1156, 2014.

[20] S. J. Camargo and A. H. Sobel, "Western North Pacific tropical cyclone intensity and ENSO," Journal of Climate, vol. 18, no. 15, pp. 2996-3006, 2005.

[21] S. J. Camargo, A. W. Robertson, S. J. Gaffney, P. Smyth, and M. Ghil, "Cluster analysis of typhoon tracks. Part II. Large-scale circulation and ENSO," Journal of Climate, vol. 20, no. 14, pp. 3654-3676, 2007.

[22] J. C. L. Chan, "Tropical cyclone activity over the western North Pacific associated with El Niño and La Niña events," Journal of Climate, vol. 13, no. 16, pp. 2960-2972, 2000. 
[23] T.-C. Chen, S.-P. Weng, N. Yamazaki, and S. Kiehne, "Interannual variation in the tropical cyclone formation over the Western North Pacific," Monthly Weather Review, vol. 126, no. 4, pp. 1080-1090, 1998.

[24] T. C. Chen, S. Y. Wang, and M. C. Yen, "Interannual variation of the tropical cyclone activity over the western North Pacific," Journal of Climate, vol. 19, no. 21, pp. 5709-5720, 2006.

[25] J. Feng, W. Chen, C.-Y. Tam, and W. Zhou, "Different impacts of El Niño and El Niño Modoki on China rainfall in the decaying phases," International Journal of Climatology, vol. 31, no. 14, pp. 2091-2101, 2011.

[26] S. K. Yoon, J. S. Kim, J. H. Lee, and Y. I. Moon, "Hydrometeorological variability in the Korean Han River Basin and its sub-watersheds during different El Niño phases," Stochastic Environmental Research and Risk Assessment, vol. 27, no. 6, pp. 1465-1477, 2013.

[27] R. Mathews and B. D. Richter, "Application of the indicators of hydrologic alteration software in environmental flow setting," Journal of the American Water Resources Association, vol. 43, no. 6, pp. 1400-1413, 2007.

[28] N. L. Poff and J. V. Ward, "Physical habitat template of lotic systems: recovery in the context of historical pattern of spatiotemporal heterogeneity," Environmental Management, vol. 14, no. 5, pp. 629-645, 1990.

[29] H. Ronghui and W. Yifang, "The influence of ENSO on the summer climate change in China and its mechanism," Advances in Atmospheric Sciences, vol. 6, no. 1, pp. 21-32, 1989.

[30] WAMIS (Water Management Information System), http:// wamis.go.kr/.

[31] NOAA (National Weather Service Climate Prediction Center), http://www.cpc.ncep.noaa.gov/data/indices/.

[32] R. Kistler, E. Kalnay, W. Collins et al., "The NCEP-NCAR 50year reanalysis: monthly means CD-ROM and documentation," Bulletin of the American Meteorological Society, vol. 82, no. 2, pp. 247-267, 2001.

[33] N. A. Rayner, D. E. Parker, E. B. Horton et al., "Global analyses of sea surface temperature, sea ice, and night marine air temperature since the late nineteenth century," Journal of Geophysical Research D: Atmospheres, vol. 108, no. 14, article 27, 2003.

[34] JMA (Japan Meteorological Agency), http://www.jma.go.jp/ jma/indexe.html.

[35] H. L. Ren and F. F. Jin, "Niño indices for two types of ENSO," Geophysical Research Letters, vol. 38, no. 4, 2011.

[36] I.-I. Lin, C.-C. Wu, I.-F. Pun, and D.-S. Ko, "Upper-ocean thermal structure and the Western North Pacific category 5 typhoons. Part I: ocean features and the category 5 typhoons' intensification," Monthly Weather Review, vol. 136, no. 9, pp. 3288-3306, 2008.

[37] Z. Zeng, Y. Wang, and C. C. Wu, "Environmental dynamical control of tropical cyclone intensity-an observational study," Monthly Weather Review, vol. 135, no. 1, pp. 38-59, 2007. 

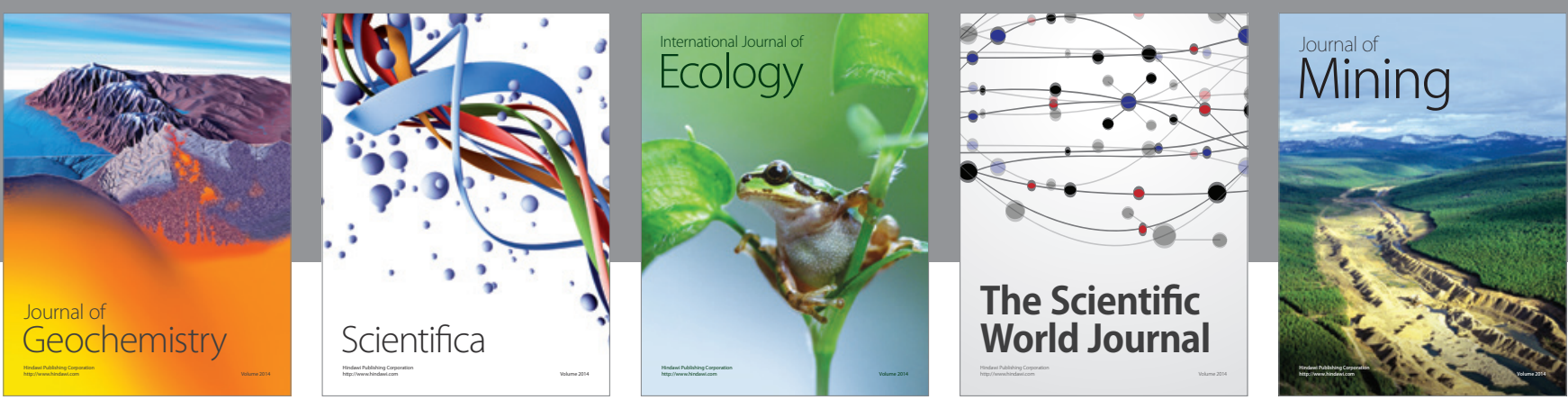

The Scientific World Journal
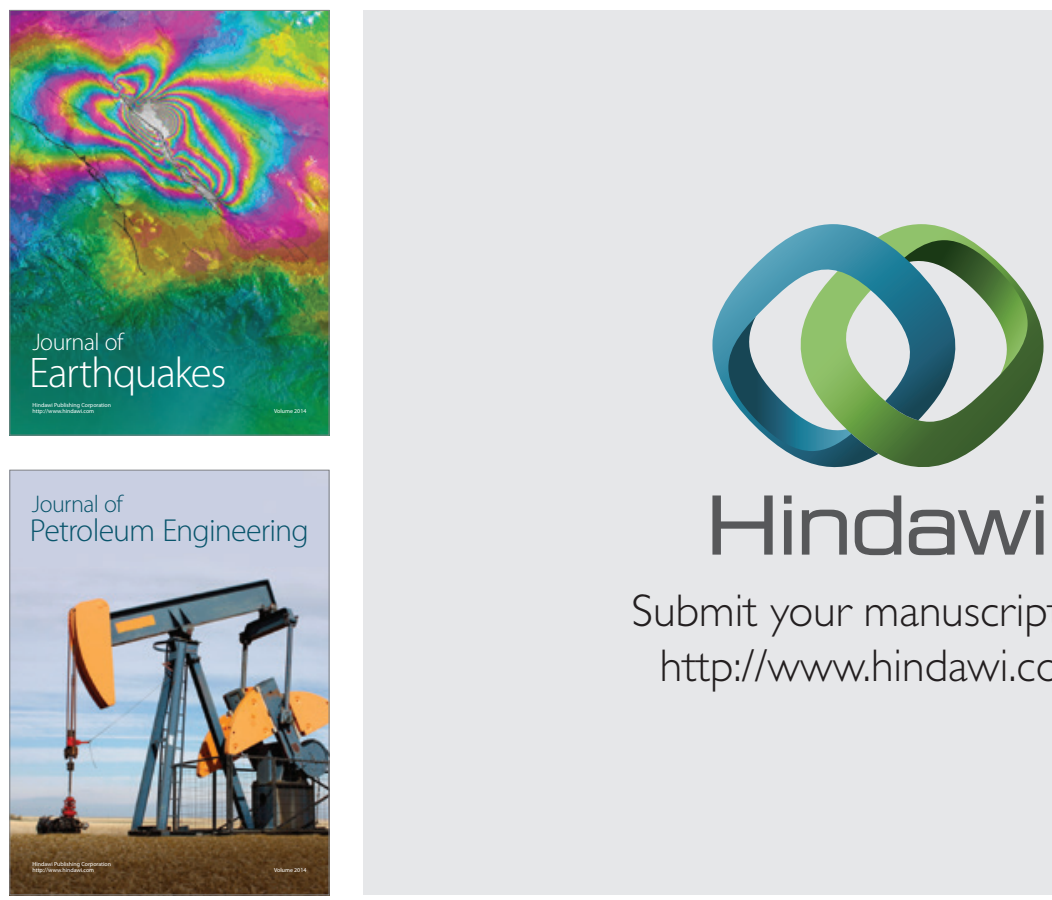

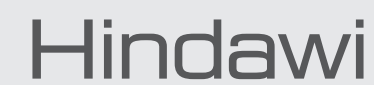

Submit your manuscripts at

http://www.hindawi.com
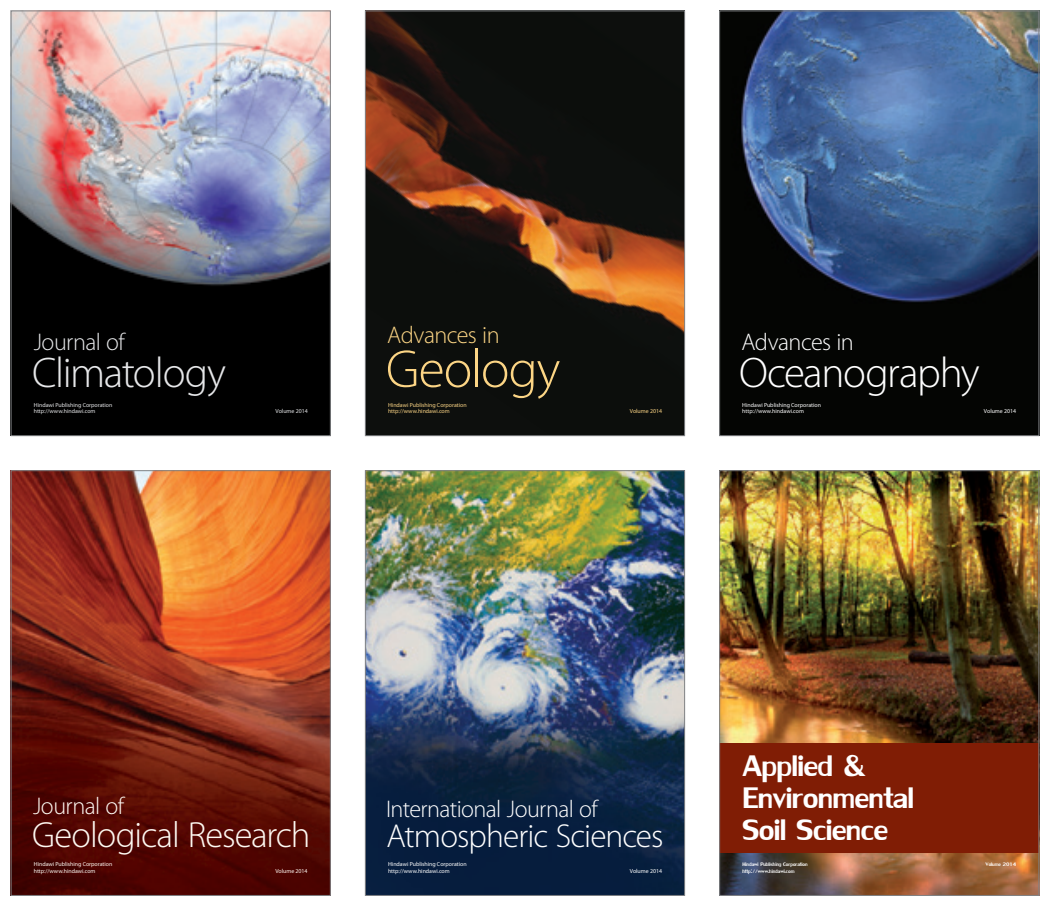
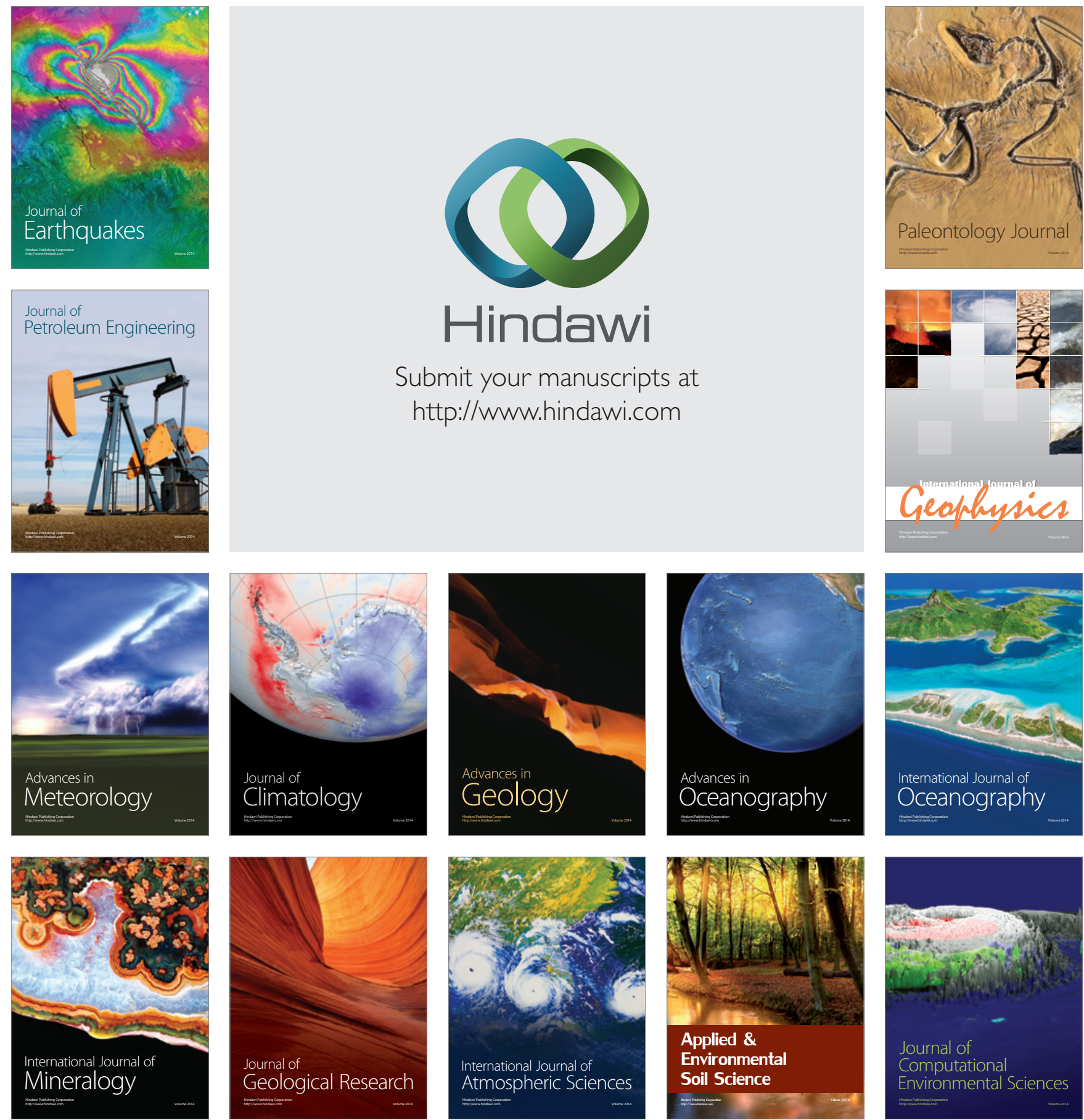